\title{
Moulins-lès-Metz - Moulins-Saint-Pierre
}

Lotissement "Les Trois Haies"

\section{Franck Gérard}

\section{(2) OpenEdition \\ 12 Journals}

Édition électronique

URL : http://journals.openedition.org/adlfi/9158

ISSN : 2114-0502

Éditeur

Ministère de la culture

Référence électronique

Franck Gérard, « Moulins-lès-Metz - Moulins-Saint-Pierre », ADLFI. Archéologie de la France-

Informations [En ligne], Lorraine, mis en ligne le 01 mars 2001, consulté le 03 mai 2019. URL : http:// journals.openedition.org/adlfi/9158

Ce document a été généré automatiquement le 3 mai 2019.

(c) Ministère de la Culture et de la Communication, CNRS 


\title{
Moulins-lès-Metz - Moulins-Saint- Pierre
}

\author{
Lotissement "Les Trois Haies"
}

Franck Gérard

\author{
Identifiant de l'opération archéologique : F1357200100098 \\ Date de l'opération : 2001 (EV)
}

Le projet de construction du lotissement «Les Trois Haies », sur la commune de Moulinslès-Metz, a entraîné le service régional de l'Archéologie de Lorraine à prescrire une opération de sondages archéologiques. L'emprise des travaux couvre une superficie de 14,5 ha. La présence d'une pépinière exploitée au moment de l'intervention archéologique a conduit à réduire cette surface à environ 10 ha.

2 Les sondages ont été réalisés à l'aide d'une pelle mécanique munie d'un godet lisse de curage de $2 \mathrm{~m}$ de large. Un total de 215 sondages de $15 \mathrm{~m}$ de long a été réalisé. Ils sont disposés en quinconce et répartis sur la totalité de l'emprise de manière à couvrir un minimum de $7 \%$ de la surface affectée par les travaux.

3 Le quartier de Moulins-Saint-Pierre est situé sur la rive droite de la Moselle, à quelques kilomètres au sud de Metz. Le projet se situe en fond de vallée, sur un terrain peu accidenté occupé actuellement par une exploitation de pépinière. La couverture végétale est épaisse de 0,30 $\mathrm{m}$. Les niveaux de graviers et de sable, situés à une profondeur moyenne de 1,20 m, sont recouverts d'une couche argilo-sableuse de couleur beige orange et de texture hétérogène et compacte. Ce niveau, dont l'épaisseur varie énormément selon les secteurs, comporte quelques inclusions fines et peu fréquentes de terre cuite et de charbon de bois. De rares zones, situées essentiellement à l'est, présentent d'importants niveaux de sable fin immédiatement sous la terre arable.

4 Aucun site archéologique structuré n'a été observé. Seuls quelques indices de sites protohistoriques et romains, ainsi que deux fosses modernes et un foyer d'essartage ont été mis au jour. 
INDEX

Index géographique : Lorraine, Moselle (57), Moulins-lès-Metz

Thèmes : charbon de bois, fosse, foyer

operation Fouille d'évaluation (EV)

AUTEURS

FRANCK GÉRARD

AFAN 